\title{
A Novel Antenna for 8 Element Beam Forming Antenna Array using Butler Matrix
}

\author{
Dilshan Singh Chadha \\ Dept. of Electrical Engineering, \\ Shiv Nadar University, \\ Greater Noida, India \\ ds964@snu.edu.in
}

\author{
Kartikeya Chaturvedi \\ Dept. of Electrical Engineering, \\ Shiv Nadar University, \\ Greater Noida, India \\ kc610@snu.edu.in
}

\author{
Madhur Deo Upadhayay \\ Dept. of Electrical Engineering, \\ Shiv Nadar University, \\ Greater Noida, India \\ madhur.upadhayay@snu.edu.in
}

\begin{abstract}
This paper presents design of novel microstrip antenna for an 8-element linear array with 8x8 Butler Matrix as a beamforming network. The proposed structure resonates at $2.4 \mathrm{GHz}$ frequency and is implemented using Microstrip Technology with FR-4 Substrate having $\varepsilon_{\mathrm{r}}=4.3$ and height=1.6 mm. Simulation results are given for the components (microstrip antenna, quadrature couplers, crossovers, phase shifters) used to implement the matrix. The 8-element antenna array is connected to the matrix to form a beamforming system and produces eight orthogonal beams at $-55^{\circ},-36^{\circ},-21^{\circ},-7^{\circ}$, $55^{\circ}, 36^{\circ}, 21^{\circ}$, and $7^{\circ}$. The reflection coefficients and isolations at all ports are below $-10 \mathrm{~dB}$ at the center frequency and side lobes of radiation pattern are sufficiently low. The applications for this technique are in lower frequency bands of $5 \mathrm{G}$ and LTE, wearable devices and IEEE 802.11 WLAN.
\end{abstract}

Keywords-Butler Matrix, Beamforming, Antenna Array, Coupler, Crossover, Radiation, 5G, WLAN.

\section{INTRODUCTION}

Today, the need for directional antennas is increasing in the world of wireless communication. A directional antenna [1] or beam antenna is an antenna which radiates or receives greater power in specific directions allowing increased performance and reduced interference from unwanted sources. Merits of beam-forming include boosting power of beams in the desired direction and the ability to withstand noisy and attenuating channel environment.

The size of electronic circuits required for wireless applications are reducing for which the microstrip technology is very much appropriate. Microstrip technique is widely used in Butler matrix due to its various advantages such as low profile, easy fabrication and less cost. [2].

The Butler matrix (BM) [3] array forms multiple fixed overlapping beams which will cover the designated angular area. It is a $N \times N$ passive feeding network with $N$ radiating elements. The output ports of the butler matrix feed the antenna elements. It is easy to implement and requires fewer components to build as compared to other networks. The loss involved is very small, which comes from the insertion loss in hybrids, phase shifters and transmission lines. We can control the direction of the beam by switching power to the desired beam port. More than one beam, or even all $N$ of them can be activated simultaneously. [4]. The primary characteristics of the Butler matrix are that inputs are isolated from each other and the phase increment between the outputs depends on which input you use [5]. Butler Matrix is a symmetric and reciprocal network, and requires lesser number of couplers and phase shifters than a traditional "divide/combine" beamforming network.

The choice for $2.4 \mathrm{GHz}$ band is because of its variety of applications which includes Bluetooth devices, cordless phones, microwave ovens, Wi-Fi standards such 802.11b, LTE and few lower frequency $5 \mathrm{G}$ bands. As all the radiating elements are implemented together, the system can provide narrow beams in different directions with higher gain as seen in the radiation patterns.

Section II explains the design and integration of the components required to implement the BM with antenna array. In Section III, simulation results including the radiation pattern are discussed followed by the conclusion mentioned in Section IV.

\section{DESIGN AND METHODOLOGY}

\section{A. Design of Microstrip Antenna}

The proposed antenna is shown in Fig 1. In this geometry, optimization over the conventional rectangular patch antenna has been done by introducing rectangular slots on the radiating patch to improve impedance matching. These slots also help in the reduction of the overall size of the antenna. For the proper placement of the inset feed, a circular slot is also introduced on the patch. Further analysis is done on the antenna by varying the radius and centre of the circular slot. An optimization study has been performed in the simulation to get the proper position of the slots and feed line to get high gain and bandwidth. The position of these slots and feed plays a vital role in creating a highperformance antenna.
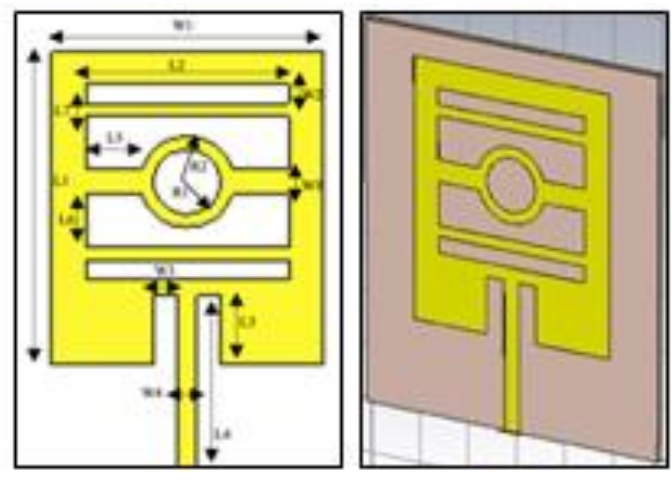

Fig. 1. Proposed Antenna Design

The substrate selected for the design is FR-4 with a dielectric constant $\varepsilon_{\mathrm{r}}=4.3$ and thickness $\mathrm{h}=1.6 \mathrm{~mm}$. The 
different dimensions related to the proposed geometry are given in Table I.

TABLE I. ANTENNA DESIGN PARAMETERS

\begin{tabular}{|c|c|}
\hline Operating Frequency & $2.4 \mathrm{GHz}$ \\
\hline Dielectric Substrate & FR-4 \\
\hline$\varepsilon_{\mathrm{r}}$ & 4.3 \\
\hline Height of Substrate & $1.6 \mathrm{~mm}$ \\
\hline Length \& Width of ground plane & $65 \times 60 \mathrm{~mm}$ \\
\hline Thickness of Ground Plane & $0.035 \mathrm{~mm}$ \\
\hline Thickness of Conductor & $0.035 \mathrm{~mm}$ \\
\hline L1 x W1 & $48 \times 40 \mathrm{~mm}$ \\
\hline Radius of smaller Circle (R1) & $5 \mathrm{~mm}$ \\
\hline Radius of Bigger Circle (R2) & $7 \mathrm{~mm}$ \\
\hline L2 & $30 \mathrm{~mm}$ \\
\hline W2 & $3 \mathrm{~mm}$ \\
\hline L3 & $10.5 \mathrm{~mm}$ \\
\hline W3 & $3.5 \mathrm{~mm}$ \\
\hline L4 & $28.5 \mathrm{~mm}$ \\
\hline W4 & $3 \mathrm{~mm}$ \\
\hline L5 & $8.29 \mathrm{~mm}$ \\
\hline W5 & $4 \mathrm{~mm}$ \\
\hline L6 & $8 \mathrm{~mm}$ \\
\hline L7 & $2 \mathrm{~mm}$ \\
\hline
\end{tabular}

\section{B. Design of $3 d B$ Branched Lined Coupler}

Quadrature coupler known as hybrid coupler or $3 \mathrm{~dB}$ coupler [6], which implies an equal distribution of power between the coupled and through ports is constructed with two quarter wavelength transmission lines having characteristic impedance of $\mathrm{Z}_{0}$, coupled by means of other two quarter wave shunt branch lines, having characteristic impedance of $Z_{0} / \sqrt{2}$ as depicted in Fig. 2. The phase difference in the two outputs arms of the device is $90^{\circ}$. It has a symmetrical property, i.e., when all the ports are matched, the power entering from one port 1 is divided into two other ports, i.e. $2 \& 3$ while the fourth port is isolated. The dimensions of the coupler are calculated and the design parameters are shown in Table II.
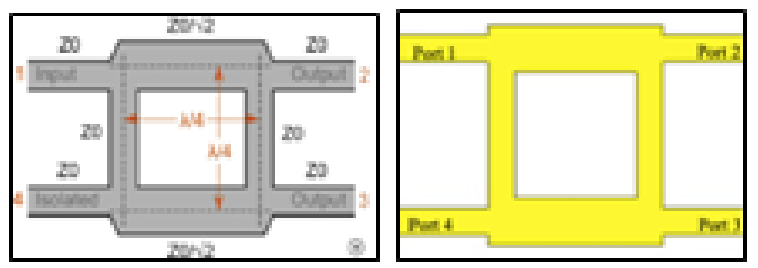

Fig. 2. 3dB Coupler Design [7]

TABLE II. 3DB COUPLER DESIGN PARAMETERS

\begin{tabular}{|c|c|}
\hline Frequency & $2.4 \mathrm{GHz}$ \\
\hline $\mathrm{Z}_{0}$ & $50 \mathrm{Ohms}$ \\
\hline $\mathrm{Z}_{0} / \sqrt{2}$ & $35.4 \mathrm{Ohms}$ \\
\hline Ground Plane & $40 \times 30 \mathrm{~mm}$ \\
\hline Thickness of Ground Plane & 0.035 \\
\hline Dielectric of Substrate $\left(\varepsilon_{\mathrm{r}}\right)$ & 4.3 \\
\hline Height of Substrate & $1.6 \mathrm{~mm}$ \\
\hline Thickness of Conductor & $0.035 \mathrm{~mm}$ \\
\hline Outer Rectangle & $24.7 \times 19.7 \mathrm{~mm}$ \\
\hline Inner Rectangle & $14.1 \times 13.7 \mathrm{~mm}$ \\
\hline Length of 4 Transmission Lines & $10.15 \mathrm{~mm}$ \\
\hline Width of 4 Transmission Lines & $3.2 \mathrm{~mm}$ \\
\hline
\end{tabular}

\section{Design of Phase Shifter}

Phase shifter is implemented by using transmission lines to create a phase delay. To create phase delay $\theta$ with microstrip line over another, extra line of length is added using Equation (1) where $\lambda_{\mathrm{g}}$ is the wavelength in the microstrip line. [8]

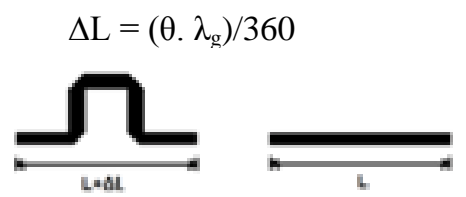

Fig. 3. Phase Shift by creating Phase Delay using Transmission Line

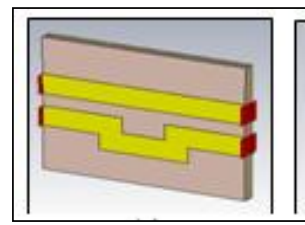

(a)

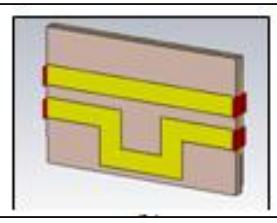

(b)
Fig. 4. Phase Shifters (a). $22.5^{\circ}$ (b). $45^{\circ}$ (c). $67.5^{\circ}$

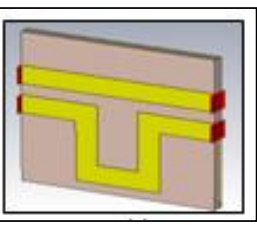

(c)
TABLE III. VALUES OF $\triangle$ L FOR REQUIRED PHASE SHIFT

\begin{tabular}{|c|c|c|}
\hline Frequency & Phase Shift & Optimized $\Delta \mathrm{L}$ \\
\hline $2.4 \mathrm{GHz}$ & $22.5^{\circ}$ & $6.1 \mathrm{~mm}$ \\
\hline $2.4 \mathrm{GHz}$ & $45^{\circ}$ & $12.4 \mathrm{~mm}$ \\
\hline $2.4 \mathrm{GHz}$ & $67.5^{\circ}$ & $21.2 \mathrm{~mm}$ \\
\hline
\end{tabular}

By adding this extra length $\Delta \mathrm{L}$, the required phase shift is introduced relatively between the two microstrip transmission lines.

\section{Design of Crossover}

The crossover is an efficient means of crossing the two microstrip transmission lines with minimal coupling between them [9]. Referring to Fig. 5, it can be observed that the implementation is made here using $50 \mathrm{Ohm}$ transmission lines and two substrates with ground plane in the middle by creating a via. The dimensions of the constructed structure are given in Table IV.
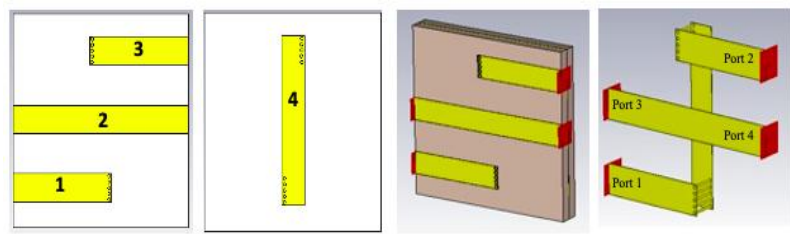

Fig. 5. Crossover Design

TABLE IV. CROSSOVER DESIGN PARAMETERS

\begin{tabular}{|c|c|}
\hline Operating Frequency & $2.4 \mathrm{GHz}$ \\
\hline Top \& Down Dielectric Substrate & FR-4 \\
\hline$\varepsilon_{\mathrm{r}}$ & 4.3 \\
\hline Height of Top \& Down Substrate & $1.6 \mathrm{~mm}$ \\
\hline Length \& Width of Substrate & $25.8 \times 25.6 \mathrm{~mm}$ \\
\hline Length \& Width of Ground Plane & $25.8 \times 25.6 \mathrm{~mm}$ \\
\hline Height of Ground Plane & $0.035 \mathrm{~mm}$ \\
\hline Thickness of Conductor (Copper) & $0.035 \mathrm{~mm}$ \\
\hline Impedance of Strips (Z) & $50 \mathrm{Ohm}$ \\
\hline Length and Width of Strip 1 & $14.5 \times 3.4 \mathrm{~mm}$ \\
\hline Length and Width of Strip 2 & $21.6 \times 3.4 \mathrm{~mm}$ \\
\hline Length and Width of Strip 3 & $14.5 \times 3.4 \mathrm{~mm}$ \\
\hline Length and Width of Strip 4 & $19.8 \times 3.4 \mathrm{~mm}$ \\
\hline Radius of Via (PEC) & $0.2 \mathrm{~mm}$ \\
\hline Height of Via & $3.67 \mathrm{~m}$ \\
\hline
\end{tabular}




\section{E. Design of $8 x 8$ Butler Matrix}

The physical implementation of the Butler Matrix is made of ten crossovers, twelve quadrature couplers and phase shifters as shown in Fig. 6 and Fig. 7. All the individual components are combined on a single substrate to implement the butler matrix. For each beam port, the circuit generates progressive phase shifts at the antenna ports. Due to the linear characteristic of the Butler matrix, eight simultaneous beams can be formed in different directions depending on the input port. [10]
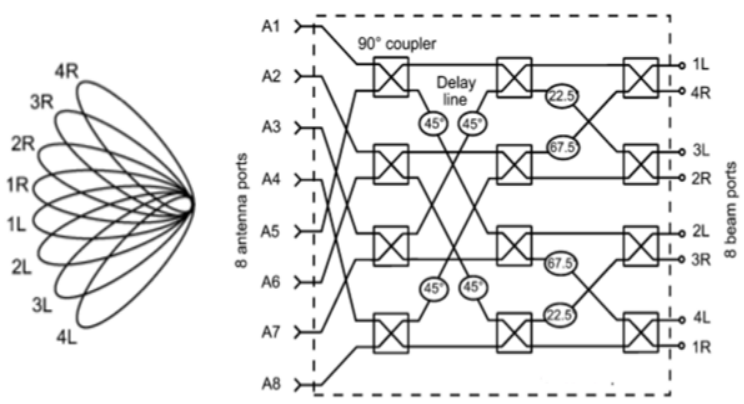

Fig. 6. BM Structure with Beamforming [10]

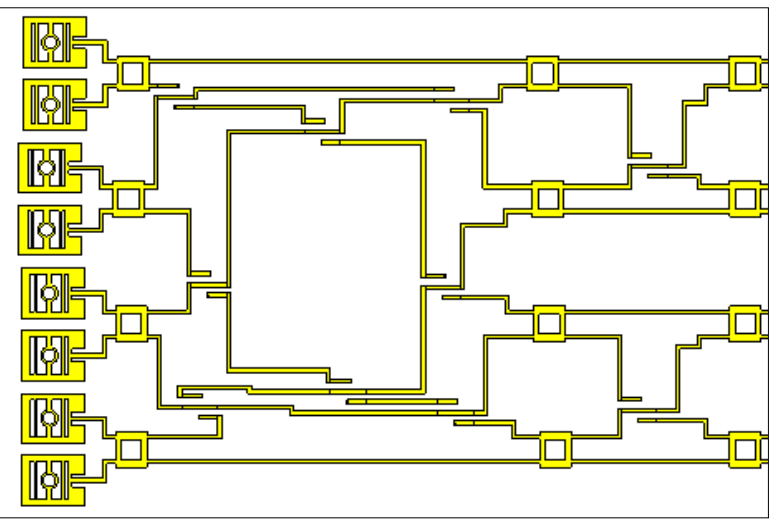

Fig. 7. Proposed BM Structure on Single FR-4 Substrate

\section{SIMULATION RESULTS AND DISCUSSION}

\section{A. Proposed Antenna Design}

The designed antenna provides a return loss less than -30 $\mathrm{dB}$ at centre frequency (Fig. 8). The antenna offers return loss bandwidth of $50.2 \mathrm{MHz}$. The radiation pattern of the antenna in 1-D is also shown (Fig. 9). HPBW (Half Power Bandwidth) along $\mathrm{Phi}=0^{\circ}$ plane is $89.6^{\circ}$ with main lobe direction $0^{\circ}$ and a gain of $5.5 \mathrm{~dB}$. Along Phi $=90^{\circ}$ plane, $\mathrm{HPBW}$ is $80.6^{\circ}$ with the direction of main lobe as $25^{\circ}$ and gain is $6.66 \mathrm{~dB}$.

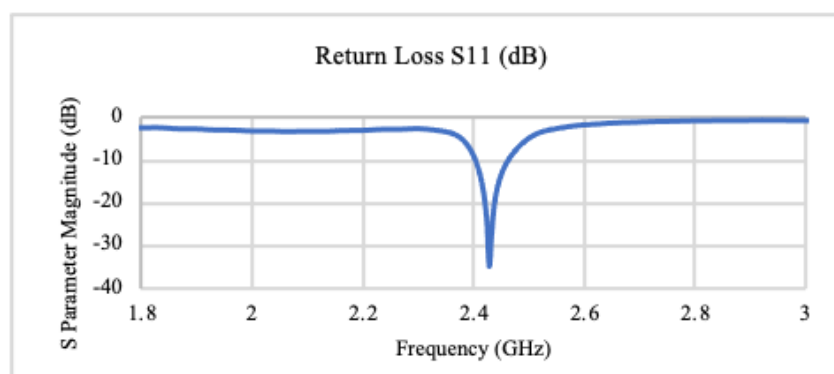

Fig. 8. Return Loss $\mathrm{S}_{11}$ for Antenna

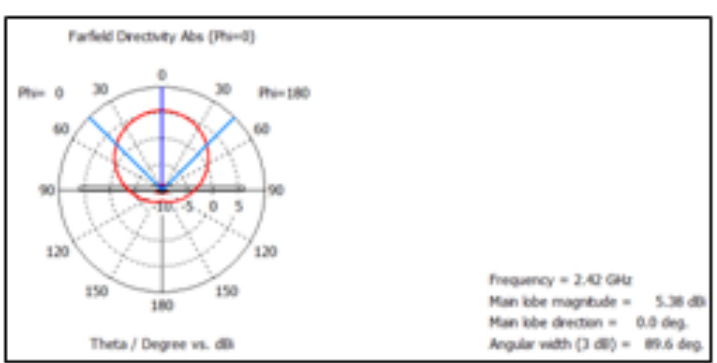

(a)

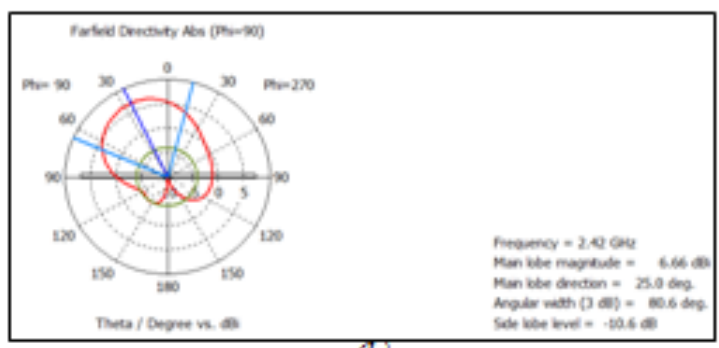

(b)

Fig. 9. Far-field Plot 1-D (a) Phi $=0^{\circ}$ (b) Phi $=90^{\circ}$

\section{B. 3 dB Coupler}

The simulated results for $3 \mathrm{~dB}$ coupler show $\mathrm{S}$ parameter characteristics i.e. $S_{11}$ to be below $-20 \mathrm{~dB}$ while $S_{21} \& S_{31}$ are at $-3 \mathrm{~dB}$ (Fig. 10). Phase difference between port 2 and port 3 is $90^{\circ}$ at the centre frequency but it is near to $90^{\circ}$ throughout the bandwidth (Fig. 11).

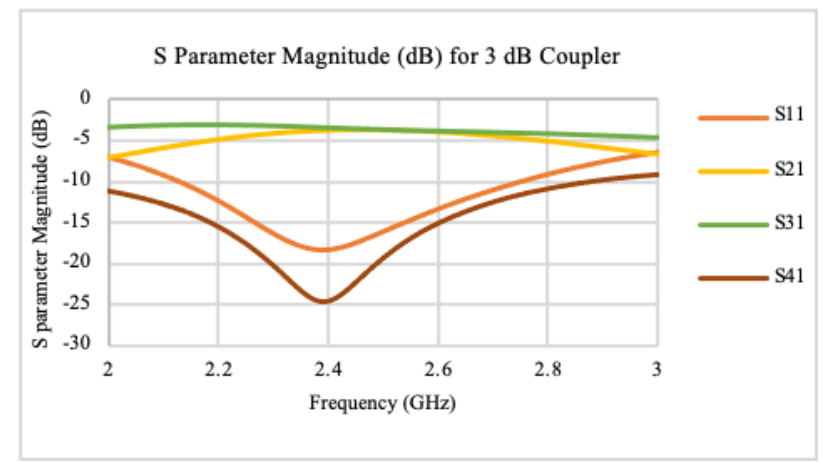

Fig. 10. S-Parameters for $3 \mathrm{~dB}$ Coupler

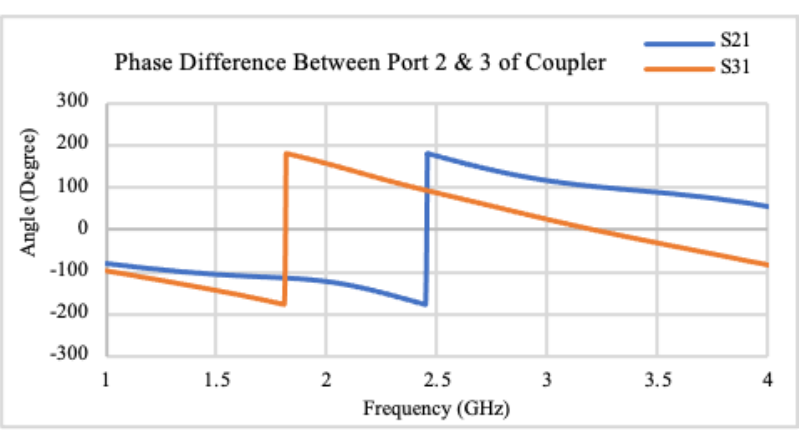

Fig. 11. Phase Difference in Port 2 and Port 3 of $3 \mathrm{~dB}$ Coupler

\section{Proposed Crossover Design}

The return loss for crossover at both input ports is below $-10 \mathrm{~dB}$ with $\mathrm{S} 21=-2.0413 \mathrm{~dB}$ and $\mathrm{S} 43=-1.5734 \mathrm{~dB}$ which is close to the ideal value of $0 \mathrm{~dB}$ implying that maximum power is transferred from Port 1 to Port 2 and from Port 3 to Port 4 at center frequency $2.4 \mathrm{GHz}$ (Fig. 12). 


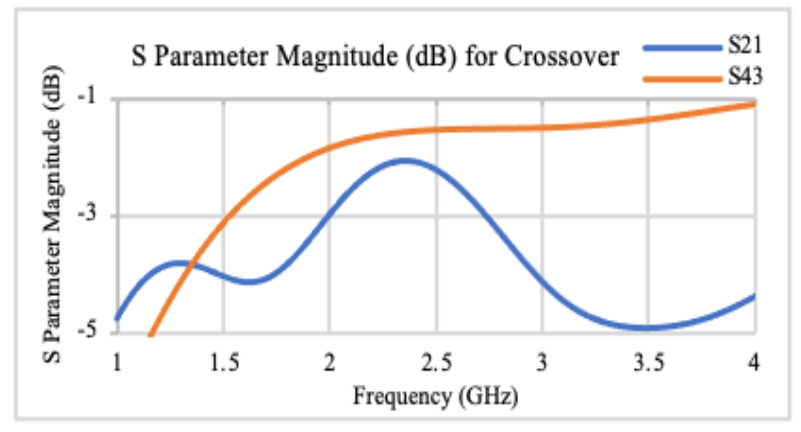

Fig. 12. $S_{21}$ and $S_{43}$ for Four Port Crossover

\section{Antenna Array using Butler Matrix}

The final layout of the optimized antenna with its beamforming network is shown in Fig.7. The eight antenna elements are equally spaced by $\lambda / 2$ at $2.4 \mathrm{GHz}$ and arranged in a linear manner [11]. Beamforming characteristics of the proposed antenna are obtained. 1-D polar far field plots for eight radiation patterns from a single input port excitation are obtained and plotted to achieve steering of beam from extreme left (4L) to extreme right (4R) (Fig. 13).

\section{TABLE V. BEAMFORMING NETWORK SIMULATION RESULT}

\begin{tabular}{|c|c|c|c|}
\hline Input Port & $\begin{array}{c}\text { Main Lobe } \\
\text { Magnitude } \\
(\mathrm{dBi})\end{array}$ & $\begin{array}{c}\text { Side Lobe } \\
\text { Level } \\
(\mathrm{dBi})\end{array}$ & $\begin{array}{c}\text { Main Lobe } \\
\text { Direction } \\
(\text { Degree })\end{array}$ \\
\hline $1 \mathrm{R}$ & 7.78 & -13.1 & 7 \\
\hline $4 \mathrm{~L}$ & 9.28 & -5.3 & -55 \\
\hline $3 \mathrm{R}$ & 9.8 & -11.1 & 36 \\
\hline $2 \mathrm{~L}$ & 8.52 & -12.2 & -21 \\
\hline $2 \mathrm{R}$ & 8.52 & -12.2 & 21 \\
\hline $3 \mathrm{~L}$ & 9.8 & -11.1 & -36 \\
\hline $4 \mathrm{R}$ & 9.27 & -5.3 & 55 \\
\hline $1 \mathrm{~L}$ & 7.79 & -13 & -7 \\
\hline $1 \mathrm{~L}+4 \mathrm{R}$ & 10.3 & -10.2 & 45 \\
\hline $3 \mathrm{R}+2 \mathrm{~L}$ & 8.09 & -12.6 & 14 \\
\hline $1 \mathrm{R}+2 \mathrm{R}+3 \mathrm{R}+4 \mathrm{R}$ & 7.72 & -13.6 & 0 \\
\hline $1 \mathrm{~L}+2 \mathrm{~L}+3 \mathrm{~L}+4 \mathrm{~L}$ & 7.72 & -13.6 & 0 \\
\hline
\end{tabular}

The minimum and maximum main lobe has a magnitude of $7.78 \mathrm{~dB}$ and $9.8 \mathrm{~dB}$ respectively. The highest sidelobe level is $-5.3 \mathrm{~dB}$ giving minimum diference between main lobe and sidelobe level of $14.5 \mathrm{~dB}$ which is the case of beam 4R. From the radiation patterns, it is seen that the angles of the eight beams associated with different inputs are $-55^{\circ}$, $-36^{\circ},-21^{\circ},-7^{\circ}, 55^{\circ}, 36^{\circ}, 21^{\circ}$, and $7^{\circ}$.

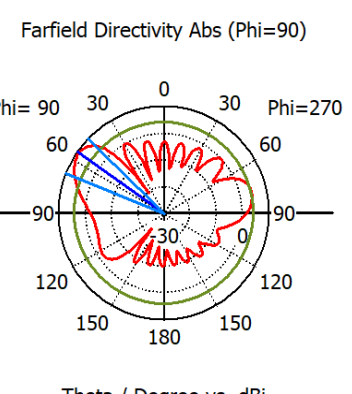

Theta / Degree vs. dBi

(a)
Farfield Directivity Abs (Phi=90)

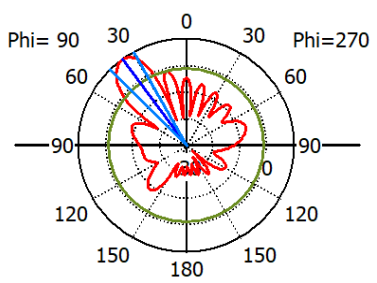

Theta / Degree vs. dBi

(b)
Farfield Directivity Abs (Phi=90)

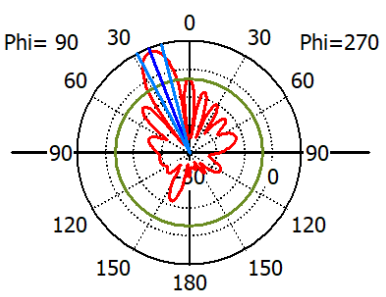

Theta / Degree vs. dBi

(c)

Farfield Directivity Abs (Phi=90)

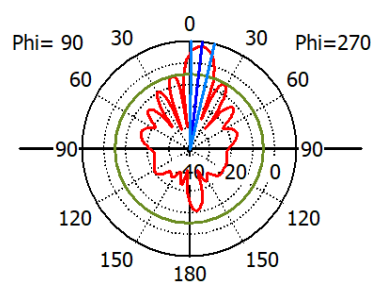

Theta / Degree vs. $\mathrm{dBi}$

(e)

Farfield Directivity Abs (Phi=90)

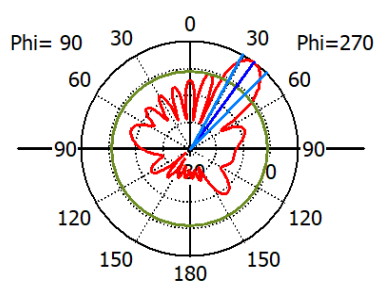

Theta / Degree vs. dB

$(g)$
Farfield Directivity Abs (Phi=90)

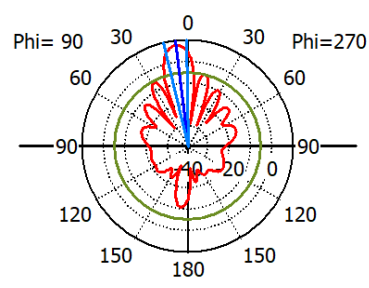

Theta / Degree vs. dBi

(d)

Farfield Directivity Abs (Phi=90)

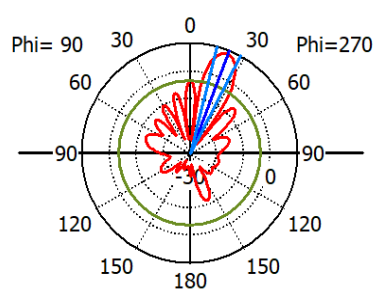

Theta / Degree vs. dBi (f)

Farfield Directivity Abs (Phi=90)

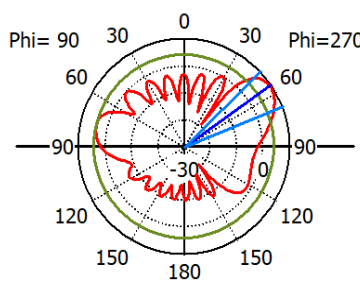

Theta / Degree vs. dBi

(h)

Fig. 13. Input Port Excited (a) $4 \mathrm{~L}$ (b) $3 \mathrm{~L}$ (c) $2 \mathrm{~L}$ (d) $1 \mathrm{~L}$ (e) $1 \mathrm{R}$ (f) $2 \mathrm{R}$ (g) $3 \mathrm{R}$ (h) $4 \mathrm{R}$

Farfield Directivity Abs (Phi=90)

Farfield Directivity Abs (Phi=90)

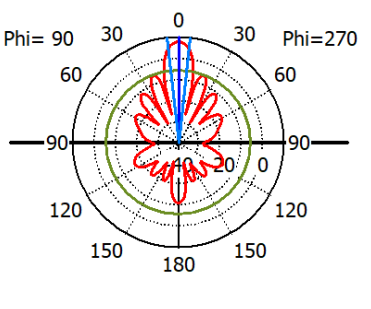

Theta / Degree vs. dBi

(a)

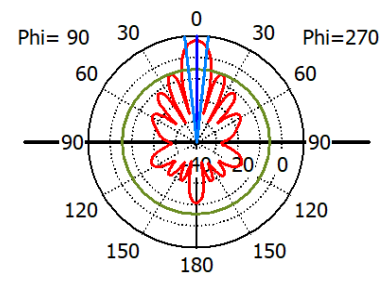

Theta / Degree vs. dBi

(b)

Fig. 14. Input Port Excited(a). $1 R+2 R+3 R+4 R$ (b) IL+2L+3L+4L

Farfield Directivity Abs (Phi=90)

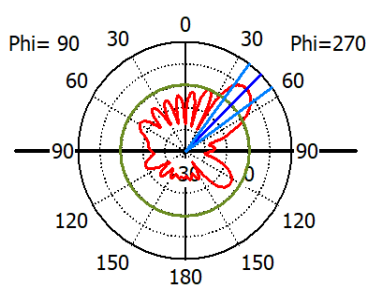

Theta / Degree vs. dBi

(a)

\section{Farfield Directivity Abs (Phi=90)}

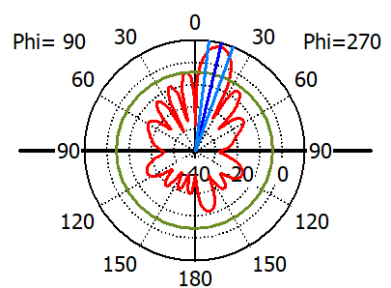

Theta / Degree vs. dBi

(b)

Fig. 15. Input Port Excited (a). 1L+4R (b) $3 R+2 L$ 
TABLE VI. PROGRESSIVE PHASE SHIFT REACHING THE ANTENNA ARRAY

\begin{tabular}{|c|c|c|c|c|c|c|c|c|}
\hline Input & 1 & 2 & 3 & 4 & 5 & 6 & 7 & 8 \\
\hline $1 \mathrm{R}$ & -382.5 & -405 & -427.5 & -450 & -472.5 & -495 & -517.5 & -540 \\
\hline 4L & -472.5 & -315 & -517.5 & -360 & -562.5 & -405 & -607.5 & -450 \\
\hline 3R & -405 & -517.5 & -270 & -382.5 & -495 & -607.5 & -360 & -472.5 \\
\hline 2L & -495 & -427.5 & -360 & -292.5 & -585 & -517.5 & -450 & -382.5 \\
\hline 2R & -382.5 & -450 & -517.5 & -585 & -292.5 & -360 & -427.5 & -495 \\
\hline 3L & -472.5 & -360 & -607.5 & -495 & -382.5 & -270 & -517.5 & -405 \\
\hline 4R & -450 & -607.5 & -405 & -562.5 & -360 & -517.5 & -315 & -472.5 \\
\hline 1L & -540 & -517.5 & -495 & -472.5 & -450 & -427.5 & -405 & -382.5 \\
\hline
\end{tabular}

The radiation pattern achieved from superposition of two signals introduced to the butler matrix at $2.4 \mathrm{GHz}$ is also shown (Fig.15). Here beam 3R is superpositioned with $2 \mathrm{~L}$ and $1 \mathrm{~L}$ with $4 \mathrm{R}$. Superposition of all $\mathrm{R}$ and $\mathrm{L}$ beams is also shown (Fig.14). The main lobe magnitude for two superpositoned beams is somewhat higher and that of all $\mathrm{L}$ and all $\mathrm{R}$ beams is slightly lower than that of the main beam direction.

\section{CONCLUSION}

The novel design of microstrip antenna is proposed to form an 8-element linear array with Butler matrix as beam forming network for wireless communication applications and has been demonstrated. It is realized using quadrature hybrid couplers, crossovers and phase shifters. The dimensions of various components of the network are initially calculated, then designed. The complete circuit (antenna array with Butler matrix feed network) is integrated on FR-4 and simulated on CST Microwave Studio. Then, it is optimized to achieve the required radiation characteristics. The simulation of the whole Butler matrix with antennas yields a maximum main lobe magnitude of 9.8 $\mathrm{dBi}$ and a minimum sidelobe level of $-13.1 \mathrm{~dB}$ for the best case. The butler matrix antenna array radiates concentrated beams in different directions when different input ports are excited. The Butler matrix has a simple structure and good radiating performance, capable of radiating eight directional beams and has acceptable gain, return losses, transmission coefficients and progressive phase difference. Based on the results obtained, the proposed design can find its application in $\mathrm{S}$ band frequency and IEEE802.11 WLAN systems as well as $4 \mathrm{G}$ and LTE.

\section{REFERENCES}

[1] Dai, Hong-Ning \& Ng, Kam-Wing \& Li, Minglu \& Wu, Min-You. (2013). An overview of using directional antennas in wireless networks. International Journal of Communication Systems. 26. 413448. 10.1002/dac.13481.J. Clerk Maxwell, A Treatise on Electricity and Magnetism, 3rd ed., vol. 2. Oxford: Clarendon, 1892, pp.68-73.

[2] Mishra, Ranjan \& Mishra, Raj \& Chaurasia, R. \& Shrivastava, Amit. (2019). Design and Analysis of Microstrip Patch Antenna for Wireless Communication. T. Divya Vani and K. R. Subhashini, "Design Approach of Multibeam Using Phased Array Antenna Aided with Butler Matrix for a Fixed Coverage Area," Progress In Electromagnetics Research B, Vol. 80, 133-149, 2018.

[3] Balling, Peter. (2005). Multibeam Antennas. 10.1002/0471654507.eme277.

[4] V.M. Jayakrishnan, and Sreedevi K. Menon. "Realization of Butlermatrix for Beamforming in Phased Array System" Procedia Computer Science, vol. 93, 2016. doi:10.1016/j.procs.2016.07.204

[5] Shobhit Kumar Mishra and Dr. B S Rai, "Survey paper on miniaturization of branch line coupler", International Journal of Technology, Innovations and Research Application, volume 14, 2015, pp 1-7.

[6] Pozar DM, Microwave Engineering (4th Edition) USA: John Wiley \& Sons.

[7] Moubadir, Mahmoud \& Aziz, Hicham \& Touhami, Naima \& Aghoutane, Mohamed \& Zeljami, K. \& Tazón, Antonio. (2015). Design and implementation of a technology planar $4 \times 4$ butler matrix for networks application. International Journal of Microwave and Optical Technology. 10. 446-451.

[8] N. S. A. Arshad, S. F. Yaacob, S. Z. Ibrahim and M. S. Razalli, "0 dB coupler employing slot technique on planar microstrip," 2014 International Conference on Computer, Communications, and Control Technology (I4CT), Langkawi, 2014, pp. 294-299, doi: 10.1109/I4CT.2014.6914192.

[9] Cetinoneri, Berke \& Atesal, Yusuf \& Rebeiz, Gabriel. (2011). An 8 times 8 Butler Matrix in 13- $\mu \mathrm{m}$ CMOS for 5-6 GHz Multibeam Applications. Microwave Theory and Techniques, IEEE Transactions on. 59. 295 - 301. 10.1109/TMTT.2010.2097751.

[10] Adamidis, George \& Vardiambasis, Ioannis \& Ioannidou, Melina \& Kapetanakis, Theodoros. (2019). Design and implementation of single-layer $4 \times 4$ and $8 \times 8$ Butler matrices for multibeam antenna arrays. International Journal of Antennas and Propagation. 2019. 112. $10.1155 / 2019 / 1645281$. 